\title{
Exploration of the New Round of College Teaching reform with Teacher as Guide
}

\author{
Shuyan $\mathrm{Yi}^{1, \mathrm{a}}$, Yao $\mathrm{Xu}^{2, \mathrm{~b},{ }^{*}}$ \\ ${ }^{1}$ College of Humanities \&Sciences of Northeast Normal University, Changchun 130117, China, \\ ${ }^{2}$ School of Changchun University of Technology, Changchun 130012, China \\ a yishuyan2013@126.com, bxuyao@ccut.edu.cn \\ *Corresponding author
}

Keywords: Teachers; Guide; Colleges and universities; Teaching Reform.

\begin{abstract}
In order to meet the needs of social development, it is imperative to reform course in institution of colleges and universities. In the course of the implementation of the teaching reform in colleges and universities, we should pay attention to the important role of the teacher as a guide, while paying attention to the subject of the students. There are differences in the ability and character between different students, and there future occupation planning are different. How to distinguish their education to different students becomes a problem that the teachers must be faced. Teachers should pay attention to the guidance of students in teaching, adopt different strategies to guide the different types of students, so that they have a stronger ability to adapt to the future life while they have wealth of knowledge, avoid the waste of resources. This teaching thinking can make the greatest possible to play the potential of students, to improve their ability, for the future into the community to lay a solid foundation. Pay attention to the guiding role of teachers, so that teachers and students to form a reform of the main linkage, which can promote the reform of the university to carry out further, to provide power for the realization of the "Chinese dream".
\end{abstract}

\section{Introduction}

China's higher education system is divided into three levels, namely, college education, undergraduate education, graduate education, and they have three different functions, namely, serving the society, cultivating talents, and scientific research. ${ }^{[1]}$ In order to meet the needs of social development, the Ministry of Education launched a new round of teaching reform of higher education in form of returning to undergraduate education in July 2015. The purpose of this reform is to focus on the improvement of students' practical ability, and strive to train every student to have scientific research ability or to master some practical skills of talents, in order to achieve the ultimate goal of serving the community. ${ }^{[2]}$

According to the training objectives of undergraduate colleges and universities, the training of undergraduate students is generally focused on two directions: one is the scientific research, two is the service society. Based on the full understanding of students, teachers should be based on different types of students in accordance with their aptitude, classification guidance for students in the specific teaching. The discussions mainly from two directions on discuss the teachers how to carry on the instruction to the students. ${ }^{[3]}$

\section{Improve students' scientific research ability}

The students who are suitable for scientific research usually have a strong ability to innovate, strong interest in novelty and strong motivation to learn, and they are good students in the teacher's eyes. In the classroom, they listen carefully and actively interact with the teachers, the difficult problems encountered in asking the teacher questions, with excellent grades; in life, they are well behaved, daily schedule is mainly found in the library and study room, can reasonable their daily living, and their future goals are clear. Most of these students have to good foundation in high schools; they 
would like to choose a lovely professional direction to continue professional graduate education. In the teaching process to these students, teachers should guide students to such aspects as the training, research and development ability on innovation ability. ${ }^{[4]}$

On the one hand, teachers can guide students to participate in innovative projects or to guide students to participate in research projects to develop their interests and ability to participate in scientific research. By participating in a specific subject, the student can master the abilities as data collection, access to information, document retrieval, data analysis, basic writing ability of scientific research papers, and this can lay a solid foundation for the future scientific research work in advance. For students who are ready to engage in high school, the teacher can introduce the students into the project which is engaged in the research of education, so that it can improve the ability of scientific research. This practical research activity has great helps to improve the students' professional quality.

On the other hand, it can be combined with the writing of undergraduate thesis to train such students' research ability. On the other hand, the graduation thesis is the final achievement of the undergraduate study for a student; the teacher can combine the writing of undergraduate thesis to train such students' research ability. In the opening stage, teachers can get effective information to guide students from many aspects, and then combined with the students' interest, learning the basic character to guide students to determine the topic of his undergraduate thesis. A case study on the professional orientation of ancient literature: Due to the character of the reasons, male students tend to be in the direction of the historical direction, around Caocao and other historical characters to study; and female students tend to choose the image of the female or the theme of love as a research topic. In process of guidance, if some students don't know how to choose the direction of their undergraduate thesis, the teachers can communicate with them, to guide their topics from the perspective of interest. Secondly, teachers should provide specific and feasible guidance to the students from the thesis outline and the writing of each chapter. In this process, teachers need to grasp the general direction, to promote students to improve the ability of scientific research for their future graduate study in advance for training.

\section{Improve students' practical operation ability}

Students who are suitable for service society tend to have no strong interest in learning, practical ability, and willing to participate in social activities, they are not suitable for further study, after graduation should find their own direction of employment. For such students, teachers should pay attention to the training of their practical ability. Teachers can not only through the relevant courses on students' oral expression, psychological quality and other aspects of early training, but also from the professional skills to guide them. In combination with the actual teaching, use the students in a certain school as an example to carry on the thorough analysis. ${ }^{[5]}$

For students engaged in education industry in the future, the Department of the school's Chinese teaching and research group carefully set up a curriculum group, respectively, from the educational theory, teaching materials research into three major directions of educational practice for students in advance for professional training and training. In these three links, the educational practice is one of the most interesting links among students, and it is also an important part of the most effective. This link is mainly implemented through the course of $<$ the middle school Chinese classroom teaching theory and practice $>$.

This course exercises on the many links that the students would be faced in their future teaching, which relates to the preparation, writing lesson plans and teaching the three processes, the three are indispensable. The former two are the foundation, for the teaching preparation, teaching is the direct embodiment of former achievements. Through the lecture, a student not only improved his psychological quality, but also familiar with the language teaching process, the most important is the ability to obtain the actual teaching gradually.

Use of Multimedia Teaching Means. There are no students who can't teach, only have the teachers who unable to teach students. This sentence shows that teachers have an important position and role in the teaching. Indeed, if the teacher's method is appropriate, it will attract the attention of 
students, to mobilize the atmosphere of classroom teaching, and achieve good teaching results. To teach this style of poetry text as an example, some students choose to play music audio while reading the text; while others are just looking for students to read aloud the text or read it by themselves. The poetry is an art of language, has a strong artistic beauty, the beauty of music. In the reading, music can heighten the atmosphere, lay the emotional tone. If there is no music to accompany, the listener is very difficult to enter the artistic conception of poetry in a limited time. It can be seen, if you want to get good teaching effect in the limited teaching time, the choice of teaching means is very important.

Teaching Method is very Important. "There is no fixed method of teaching, the key is to choose a good method” is an important rule in the field of education. It emphasizes that teachers' teaching methods should be selected according to the students' cognitive rules. Such as: from simple to complex; from known to unknown; from the near to the distant; from the outside to the inside; from the concrete to the abstract; from quantitative to qualitative change; from practice to theory, then from theory to practice and so on. These are the cognitive laws of nature, but also the cognitive law of the students.

Under the premise of following these basic rules, teachers can freely arrange their own teaching contents. In the lecture, some students do not fully prepare, excessive dependence on handouts, little interaction with the students, basically is the answer, since the circle of self portraits. This is a failed teaching method. Good teaching is the method that through the using of heuristic language, setting the problems, so that making the students getting into the teaching content step by step. Thus, the students from "want me to learn" into "I want to learn" in the classroom, their subjective initiative to mobilize, the teaching effect is good. Through this kind of simulation classroom teaching, can let the student realize the teaching is not the teacher a person's matter, the student also is one of important factors. This change will allow students to learn empathy, to provide a reference for their daily after teaching.

Promote the Change of Students' Identity. Learning and teaching are two completely different behaviors. Generally speaking, learning is performed by students, whose goal is to point to the specific knowledge of each subject, that is, to solve the problem of "what", while teaching is the behavior of the teacher to complete, is to solve the "why" problem. Teaching behavior requires the teachers to have higher professional ability, "it is not only know what, but also know why".

For a long time, the student just play the role of the recipient of knowledge in the traditional mode of education, and take a high score is the direct embodiment of their ability. After graduation, especially after entering the post of Teachers, they will be involved in the conversion of students to teachers, if there is no sufficient understanding, this process will waste them a lot of time. Through the course of "the middle school Chinese classroom teaching theory and practice", teachers can be in advance for students in the future work will encounter problems to explain, guide students to achieve psychological changes in advance. The teaching link is an important way to cultivate the students change from knowledge accepter to knowledge initiator.

At the beginning of the lecture in the lecture, most of the students have the following two questions: One is that some students are not fully aware of the importance of teaching, can't adapt to the role of the conversion and complete the trial as a task, they only teach knowledge by reading lesson plans; two is that some students only consider their own lectures, did not take into account the students' ability to accept lectures. In the first case, the students are usually more introverted personality, they are not willing to show themselves in public places; they look nervous and speech disorder when lectures, who are not fully adapted to the role of teachers. In the second kinds of situations, the students are relatively cheerful personality, willing to show their own; there are too many personal performance, they often lecture speed too fast and lack of interaction with the students, do not take care of the students in class, like a person in the report. It can be said that the teaching effect of these two forms is very small.

There is always a process of adaptation, students appear not adapt to the situation in the first lecture is very normal. From the above results, after accepted the teacher's and the students' comments on the first trial, many students realized their own problems and carried out some targeted training. In the second lecture, most students have great progress. 
Help the Students Improve Their Psychological Quality. The traditional education pays much attention to the students' performance, and neglects the cultivation of students' psychological quality. With the development of society, the improvement of humanistic quality is becoming more and more important, and the cultivation of mental health of the students becomes the consensus of all walks of life. The goal of teaching reform in Colleges and universities is to provide the society with high quality labor force. This requires the college graduates not only should have a good business ability and rich theoretical knowledge, but also should have a good psychological quality. Psychological quality is an invisible ability; it is an important prerequisite for a person to achieve a variety of professional ability and foundation.

Through the lecture, not only can improve the students' practical teaching ability, also can exercise their guts, improve their psychological quality. Through the teaching performance of students can be seen: the psychological quality and the teaching level, teaching effect is very subtle. Lecture is a concentrated expression of the comprehensive ability of students, it can not only show the students' literary attainments, professional knowledge, but also can be an immediate reflection of the psychological quality of a student. Because there is no lecture in public before experience, some students are often in the first trial when nervous; performance logic language is poor, even to speak incoherently, anacoluthon. After the first failure experience, some students will be better in the second class; they express better in language, and their teaching effects had greatly improved.

Through the practice exercise, the students not only get the confidence and courage of speaking in public, but also find the realization of self value. This is not only beneficial to them quickly adapt to the role of teachers, but also have a positive impact on their entire life.

\section{Summary}

In short, the college education reform should not only pay attention to the students as the main body, and make a clear planning for the students of different personality in advance; also should give full play to the leading role of teachers. Through the active guidance of teachers, improve the students' ability to adapt to the community, and provide support for their future works. Through the variety of practical activities, the students' initiative will be fully played, so that each student can be successful. In this way, we can really put the national advocacy of college education reform into effect.

\section{Acknowledgments}

This paper is one of the initial results of the teaching and scientific project of Jilin Province (the number of this project is GH16156), and Yao Xu is the Corresponding author of this paper.

\section{References}

[1]. K.N. Wu, On the foundation of successful education reform. Educational Research, General. 384 (2012) No. 1, pp.24-31.

[2]. Y.F. Yang. Some considerations on deepening the comprehensive reform in education. Educational Research. General. 408 (2014).No. 1, pp.4-19.

[3]. X. Mao. Study on the characteristics of the competency of college counsellors and the Countermeasures. Studies in Ideological Education. General. 232 (2014) No. 1, pp.102-104.

[4]. K.D. Yin. Strengthening the construction of dormitory culture and improve students' comprehensive quality of college students. Education Exploration. (2008) No. 1, pp. 4-5.

[5]. Y.M. Ding. Rethinking on the Role and Quality of Teachers of University Enterprising Education in the Innovation Situation. Heilongjiang Researches on Higher Education. (2015)NO.12, pp. 68-70. 